\title{
Correction to: Intelligent-activated carbon prepared from pistachio shells precursor for effective adsorption of heavy metals from industrial waste of copper mine
}

\author{
Vajihe Nejadshafiee ${ }^{1,2} \cdot$ Mohammad Reza Islami $^{1}$
}

\section{Published online: 14 January 2020}

(C) Springer-Verlag GmbH Germany, part of Springer Nature 2020

\section{Correction to: Environmental Science and Pollution Research} https://doi.org/10.1007/s11356-019-06732-4

The original publication of this paper contains a mistake.

The correct figure images are presented in this paper.

The original article was corrected.

The online version of the original article can be found at https://doi.org/ 10.1007/s11356-019-06732-4

\section{Vajihe Nejadshafiee}

nejadshafiee@sci.uk.ac.ir

1 Chemistry Department, Shahid Bahonar University of Kerman, Kerman 76169, Iran

2 Central Lab, Shahid Bahonar University of Kerman, Kerman 76169 , Iran 


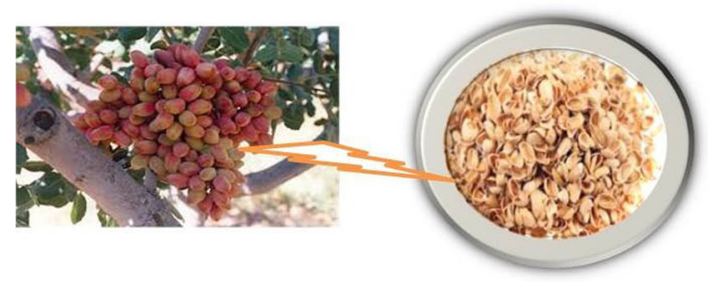

1) Carbonization

2) Activation

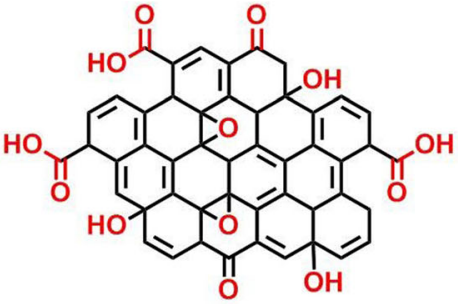

$\mathrm{AC}$

1) $\mathrm{FeCl}_{3}, 6 \mathrm{H}_{2} \mathrm{O}$

2) $\mathrm{Na}_{2} \mathrm{~S}_{2} \mathrm{O}_{3}$

3) $\mathrm{NH}_{3}(\mathrm{aq})$

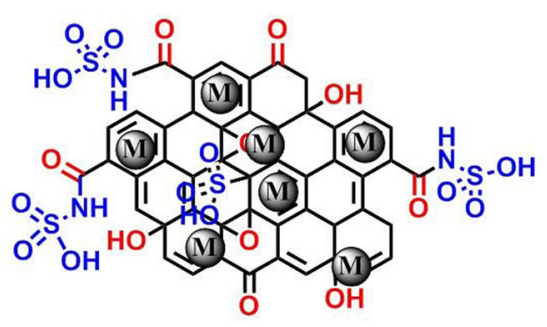

$\mathrm{H}_{2} \mathrm{NSO}_{3}$-MAC NCs

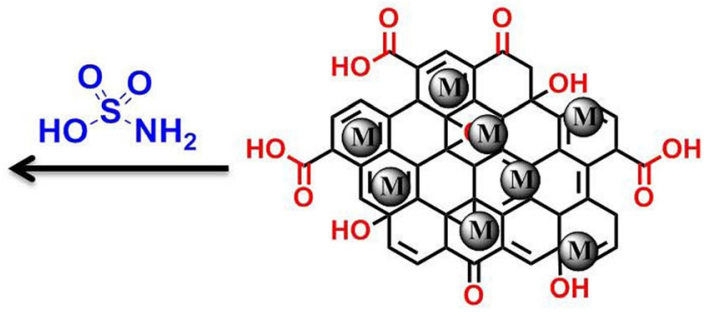

MAC

Scheme 1 The general route for the preparation of $\mathrm{AC}, \mathrm{MAC}$, and $\mathrm{H}_{2} \mathrm{NSO}_{3}-\mathrm{MAC} \mathrm{NCs}$

Scheme 2 Proposed mechanism for the chelation of $\mathrm{Cu}(\mathrm{II})$ onto $\mathrm{H}_{2} \mathrm{NSO}_{3}$-MAC NCs

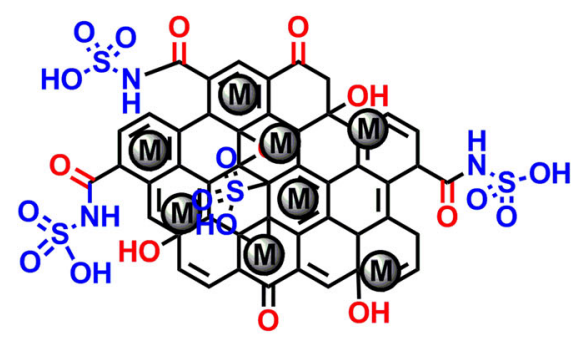

$\stackrel{\mathrm{Cu}(\mathrm{II})}{\longrightarrow}$ 
Fig. 1 TEM images of a AC-H, b $\mathrm{MAC}$, and $\mathbf{c} \mathrm{H}_{2} \mathrm{NSO}_{3}-\mathrm{MAC} \mathrm{NCs}$
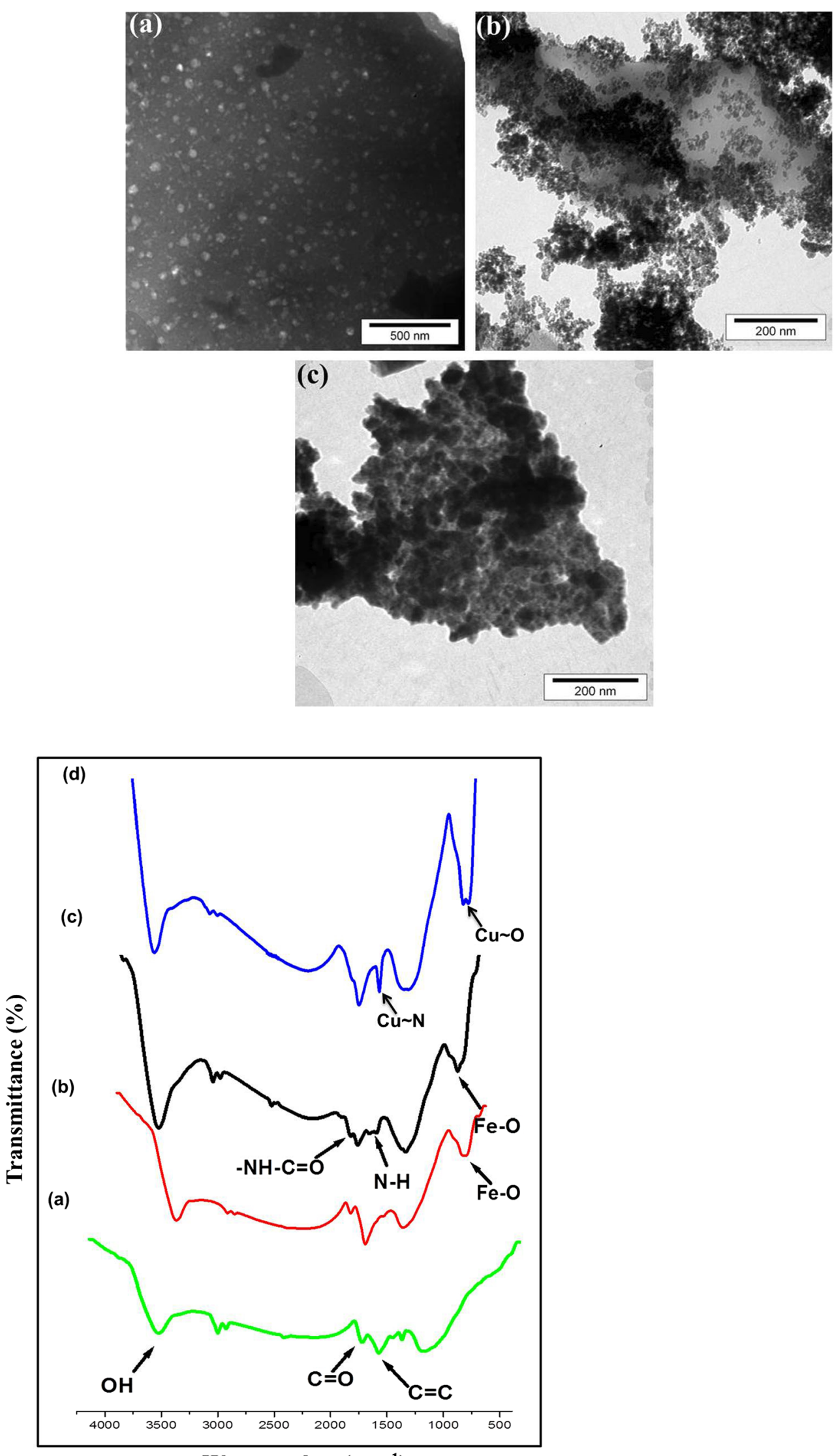

Wavenumber $\left(\mathrm{cm}^{-1}\right)$

Fig. 2 FT-IR spectra of a AC, b MAC, $\mathbf{c} \mathrm{H}_{2} \mathrm{NSO}_{3}$-MAC NCs, and $\mathbf{d} \mathrm{H}_{2} \mathrm{NSO}_{3}-\mathrm{MAC} \mathrm{NCs}-\mathrm{Cu}$ (II) 


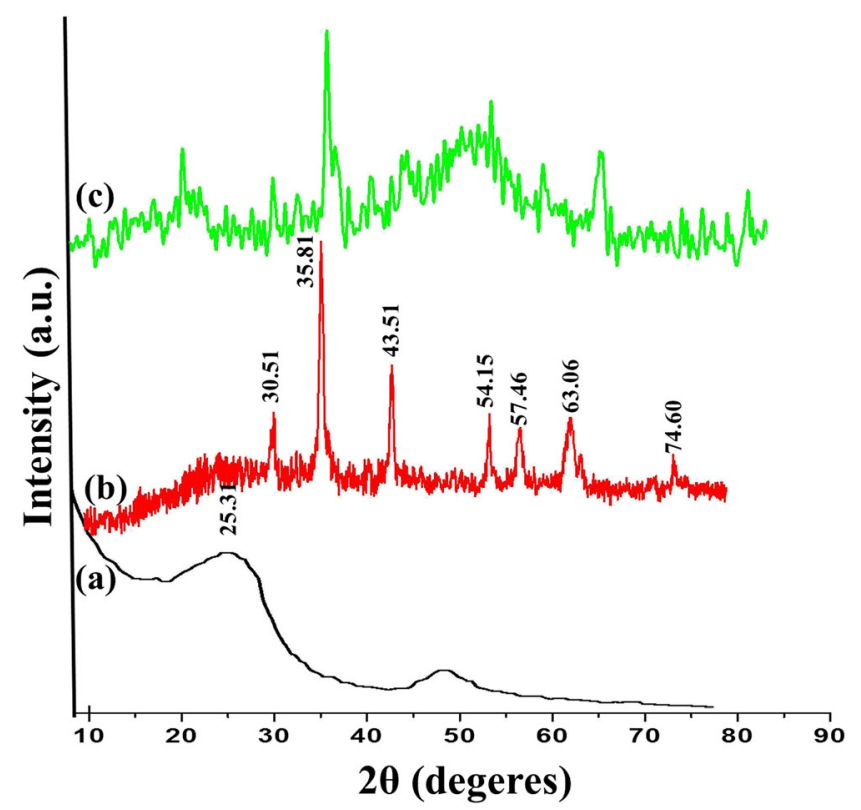

Fig. 3 XRD patterns of a AC-H, b MAC and $\mathrm{H}_{2} \mathrm{NSO}_{3}-\mathrm{MAC} \mathrm{NCs}$

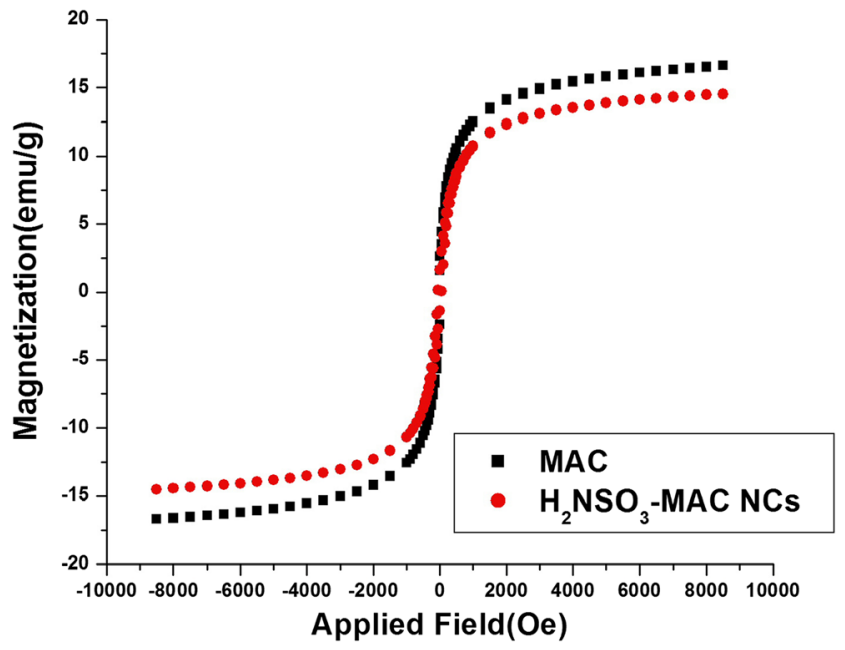

Fig. 4 Magnetization curves of MAC and $\mathrm{H}_{2} \mathrm{NSO}_{3}$-MAC NCs 
Fig. 5 TGA plots of a AC-H, $\mathrm{MAC}$, and $\mathrm{H}_{2} \mathrm{NSO}_{3}-\mathrm{MAC} \mathrm{NCs}$ and $\mathbf{b} \mathrm{H}_{2} \mathrm{NSO}_{3}-\mathrm{MAC} \mathrm{NCs}-\mathrm{Cu}$
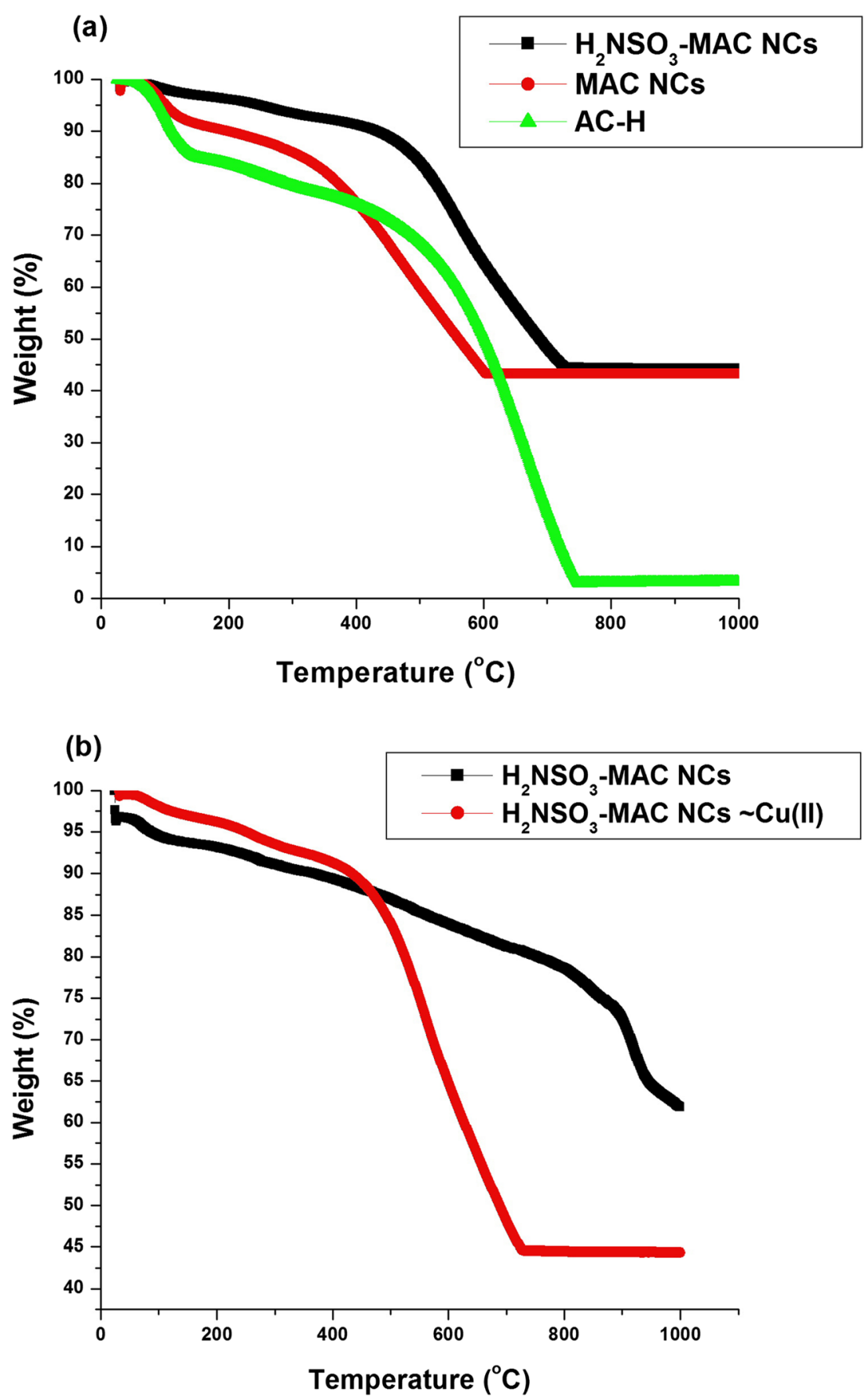


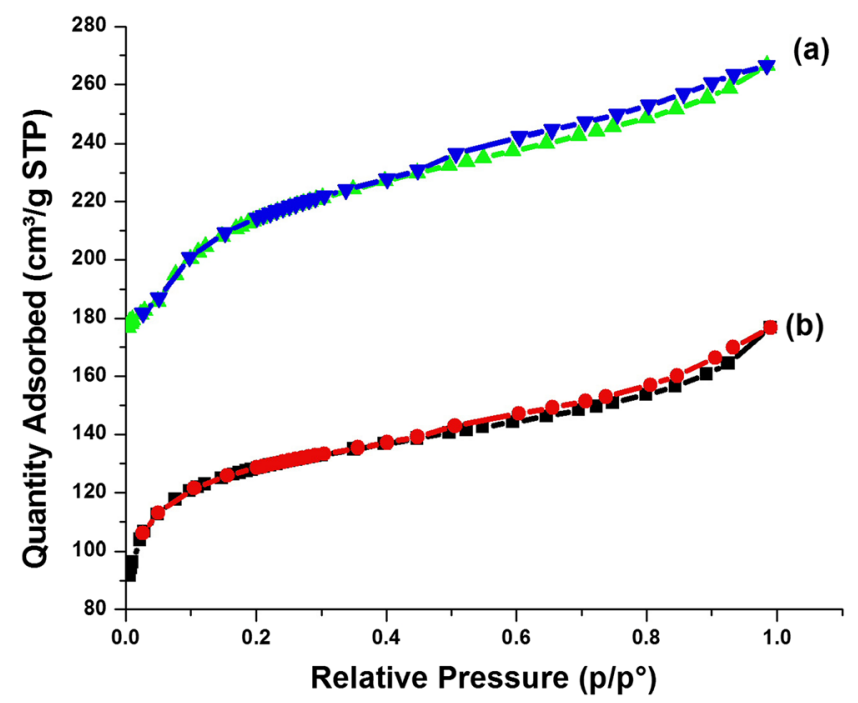

Fig. $6 \mathrm{~N}_{2}$ adsorption-desorption isotherms for $\mathbf{a} \mathrm{AC}-\mathrm{H}$ and $\mathbf{b} \mathrm{H}_{2} \mathrm{NSO}_{3}-\mathrm{MAC} \mathrm{NCs}$
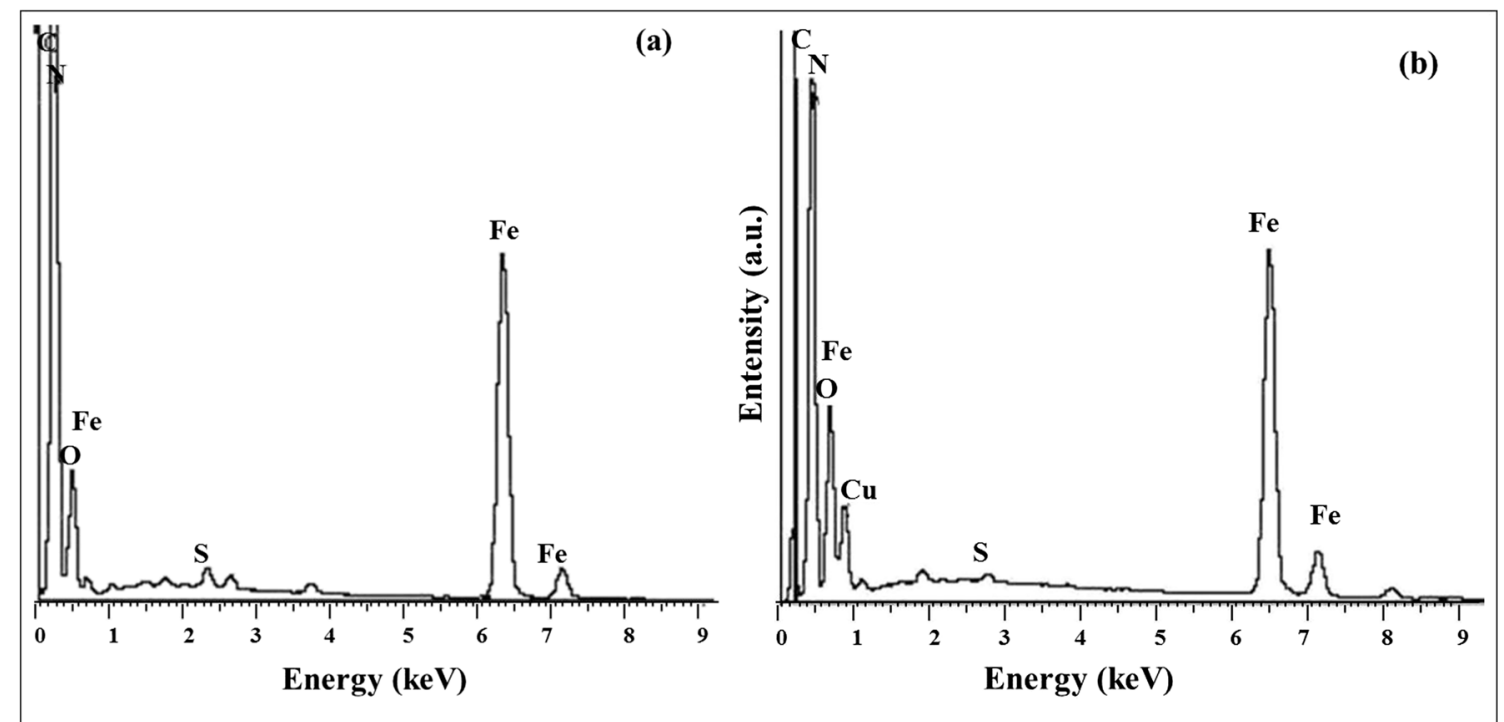

Fig. 7 EDS pattern of $\mathbf{a} \mathrm{H}_{2} \mathrm{NSO}_{3}$-MAC NCs and $\mathbf{b} \mathrm{H}_{2} \mathrm{NSO}_{3}-\mathrm{MAC} \mathrm{NCs}-\mathrm{Cu}$ 
(a)

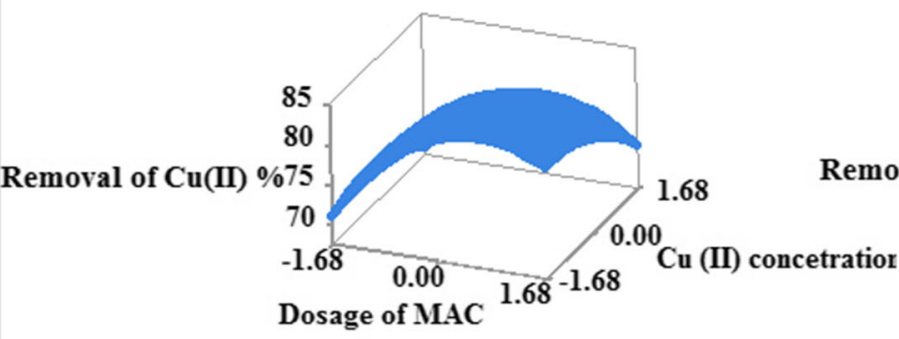

(c)

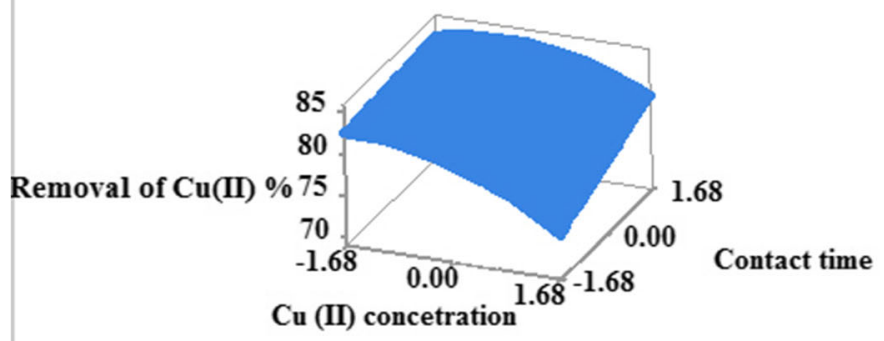

Fig. 8 The 3D plots exhibit the effect of a dosage of $\mathrm{H}_{2} \mathrm{NSO}_{3}-\mathrm{MAC} \mathrm{NCs}$ and $\mathrm{Cu}$ (II) concentration, $\mathbf{b}$ dosage of $\mathrm{H}_{2} \mathrm{NSO}_{3}-\mathrm{MAC}_{\mathrm{NCs}}$ and contact time, and $\mathbf{c} \mathrm{Cu}(\mathrm{II})$ concentration and contact time (b)

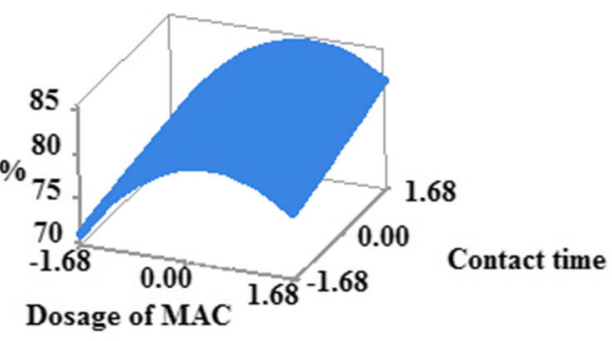

Dosage of MAC 


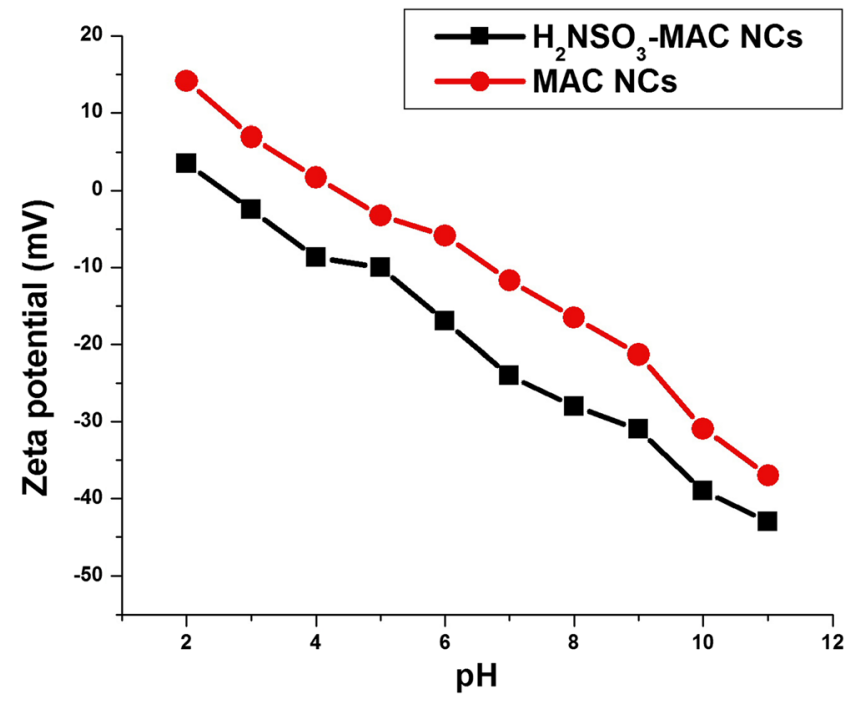

Fig. 10 Zeta potential of MAC and $\mathrm{H}_{2} \mathrm{NSO}_{3}-\mathrm{MAC} \mathrm{NCs}$

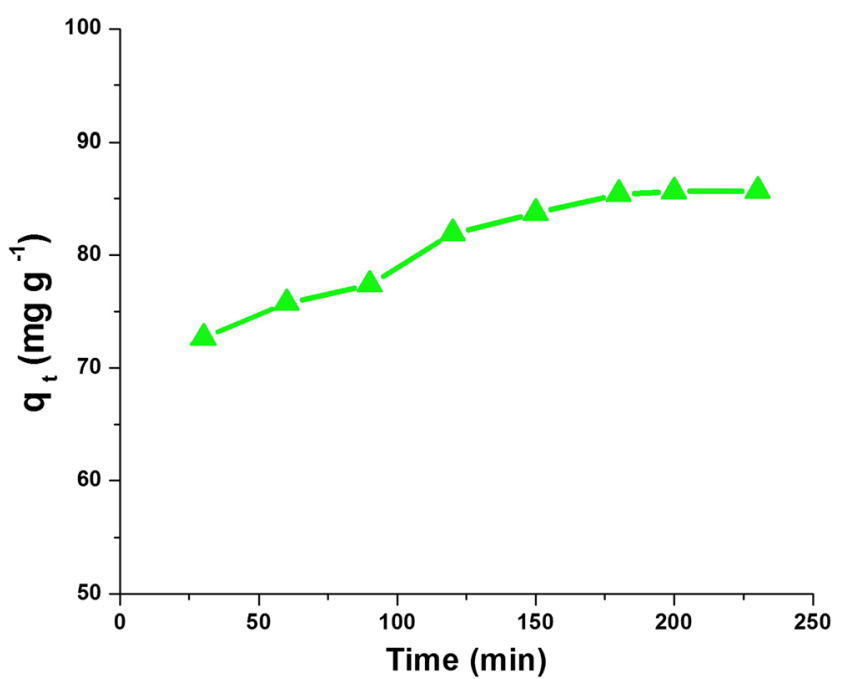

Fig. 11 Adsorption kinetic of $\mathrm{Cu}$ (II) on $\mathrm{H}_{2} \mathrm{NSO}_{3}$-MAC NCs 

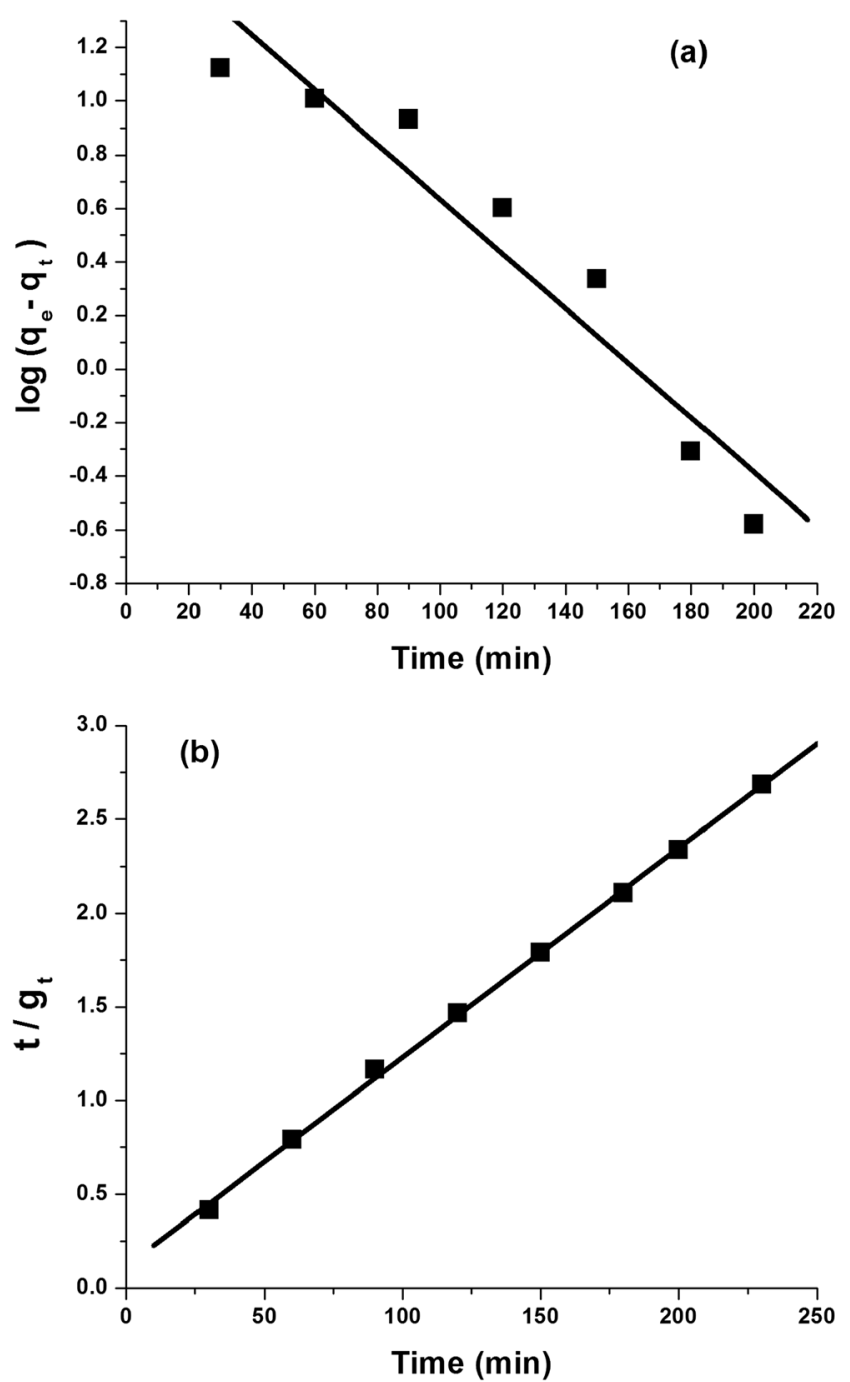

Fig. 12 Kinetic adsorption of $\mathrm{Cu}$ (II) ions on $\mathrm{H}_{2} \mathrm{NSO}_{3}$-MAC NCs: a pseudo-first-order model and $\mathbf{b}$ pseudo-second-order models model

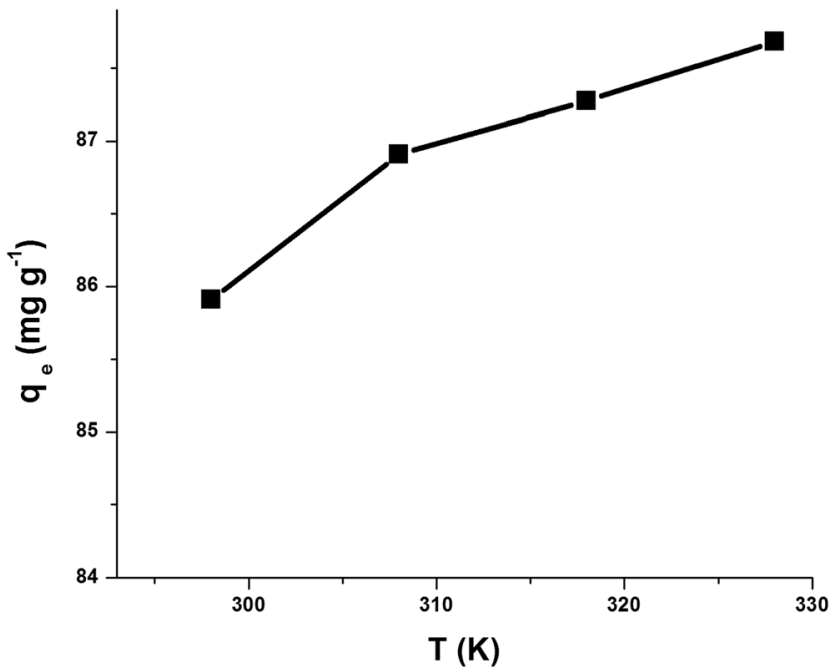

Fig. 13 Effect of temperature on adsorption capacity of $\mathrm{H}_{2} \mathrm{NSO}_{3}-\mathrm{MAC} \mathrm{NCs}$ for $\mathrm{Cu}(\mathrm{II})$ ions $\left(\mathrm{C}_{\mathrm{i}}=60 \mathrm{mg} \mathrm{L}{ }^{-1}, \mathrm{M} / \mathrm{V}=0.6 \mathrm{~g} \mathrm{~L}-1=180 \mathrm{~min}, \mathrm{pH}=6.5\right)$ 
Fig. 14 Adsorption isotherms of $\mathrm{Cu}$ (II) ions on the AC-H, MAC, and $\mathrm{H}_{2} \mathrm{NSO}_{3}$-MAC NCs
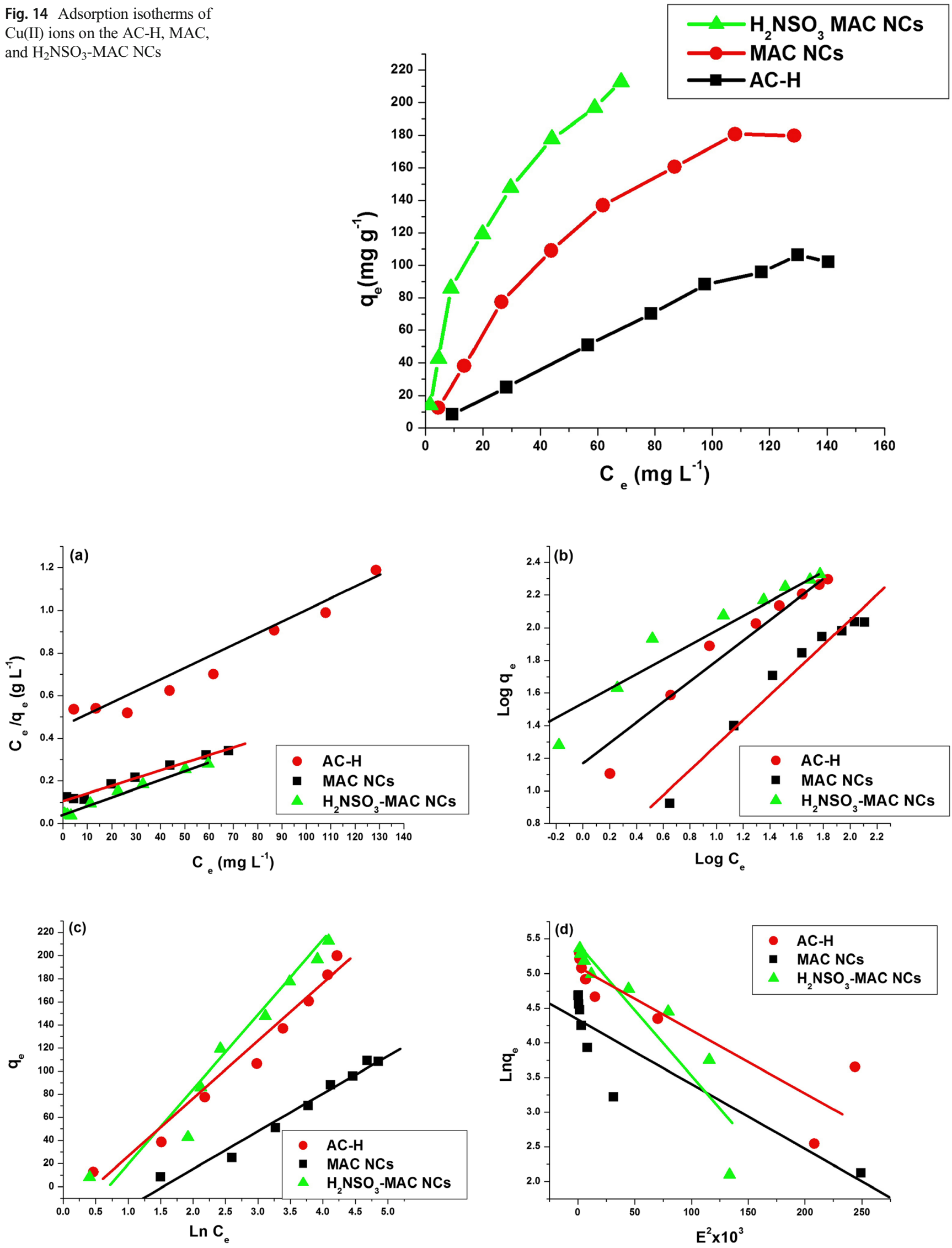

Fig. 15 a Langmuir, b Freundlich, $\mathbf{c}$ Temkin, and $\mathbf{d}$ DR isotherms for the adsorption of $\mathrm{Cu}(\mathrm{II})$ ions onto AC-H, $\mathrm{MAC}$ and $\mathrm{H}_{2} \mathrm{NSO}_{3}-\mathrm{MAC} \mathrm{NCs}^{-}$ 